\title{
MODELING STRATEGIES FOR THE LATERAL RESPONSE OF CURVED SURFACE SLIDER DEVICES UNDER EXTREME DISPLACEMENT DEMANDS
}

\author{
Marco Furinghetti ${ }^{1,2}$ and Alberto Pavese ${ }^{1}$ \\ ${ }^{1}$ University of Pavia \\ Via Ferrata 3, 27100 Pavia (Italy) \\ marco.furinghetti@unipv.it \\ a.pavese@unipv.it \\ ${ }^{2}$ EUCENTRE \\ Via Ferrata 1, 27100 Pavia (Italy) \\ marco.furinghetti@eucentre.it
}

\begin{abstract}
Base isolation represents one of the most efficient strategy for the reduction of the structural vulnerability of buildings and bridges. Design procedures generally aim to provide the proper period shift, in order to reduce spectral acceleration values and, consequently, the base shear and internal forces. On the other hand, high displacement demands can be achieved, which can be partially limited by providing dissipative capacity through hysteretic behaviors. Although design procedures allow to fairly estimate the design displacement of the adopted devices, extreme seismic event can occur, and displacement higher than the design value can be experienced. Especially for Curved Surface Slider devices, if the displacement demand exceeds a certain geometrical limit, non-negligible damage can occur at the sliding pad, and variations in the force response are consequently noticed.

In this work modeling strategies for the computation of the seismic response of base-isolated buildings are presented, by considering extreme earthquake loading conditions. Analytical models are reported for Curved Surface Slider devices, calibrated through the experimental outcomes of tests performed at the Laboratory of EUCENTRE Foundation in Pavia (Italy). In addition, simplified dynamic systems are defined, which allow fast assessments of the global response of a base-isolated structure, even though extreme seismic events are applied. Results have been compared to the response returned by an experimental hybrid simulation, in order to evaluate the accuracy of the presented dynamic systems.
\end{abstract}

Keywords: Base isolation, Curved Surface Slider, extreme earthquake loading, dynamic system, experimental hybrid simulation. 


\section{INTRODUCTION}

Recent research works about seismic isolation have led to the definition of several modeling strategies for isolators, models which can be adopted in time history analyses for the assessment to building and bridge structural systems, by reducing significantly the uncertainty of the structural behavior prediction ([1], [7], [16]). The design of the proper period elongation, internal forces in the superstructure elements can be significantly reduced; on the other hand a large displacement demand may occur at the isolation level, even though lower values can be achieved, by means of the hysteretic characteristics of the implemented devices. Curved Surface Slider devices, among the others, represent one of the most suitable solutions for baseisolation ([2], [3], [10], [12], [13], [14]). Such isolators can actually accommodate large displacement demands, with potentially high dissipative capacities, which are provided by the frictional response of the induced sliding motion. In addition, residual displacements are effectively limited by the recentering behavior, due to the spherical shape of the sliding surfaces. However, recent risk assessment studies have shown that the base isolation technique in some cases can lead to higher seismic risk, with respect to their a correspondent fixed-base configuration. This is an unexpected outcome, since the isolation system is supposed to protect the superstructure against the effects of earthquake excitations. The main reason behind such results is related to the definition of the collapse condition that has is commonly assumed for isolation devices, which consists of the achievement of the design displacement. More specifically, a sliding base isolator is assumed to collapse once the internal reaches the edge of the implemented sliding surfaces, which corresponds to the maximum stroke of the device. This condition is generally considered as the maximum limit of the displacement capacity for sliding devices, because it is associated to the loss of functionality of the isolator. However, recent experimental research has led to evidence of extra-displacement capacity for such devices, with a controlled and limited force response ([6][8]); furthermore, the outcomes have been used for both model calibration and vulnerability assessments, in order to account for the effective ultimate conditions of the implemented isolators.

In this work the extra-stroke behavior of Double Curved Surface Slider devices has been modeled, in order to evaluate the response of a base isolated case study structure, subjected to a severe seismic event. An easy to implement analytical model of the extra-design response has been adopted, among the strategies available in the very recent literature, and results have been compared to a hybrid simulation, which has been performed at the Laboratory of EUCENTRE Foundation in Pavia (Italy). The outcomes of both the experimental hybrid and numerical simulations have been analyzed, in terms of isolation displacement and hysteretic responses, cumulative damage at the sliding pads equipped in the physical device and building base shear time series.

\section{CASE STUDY STRUCTURE}

The case study structure adopted in this research work consists of a reinforced concrete frame structure, which has been modeled by means of linear-elastic frame elements, by considering a reinforced concrete slab as an interface between the superstructure and the isolation layer, implemented through a mesh of shell elements (Figure 1). 

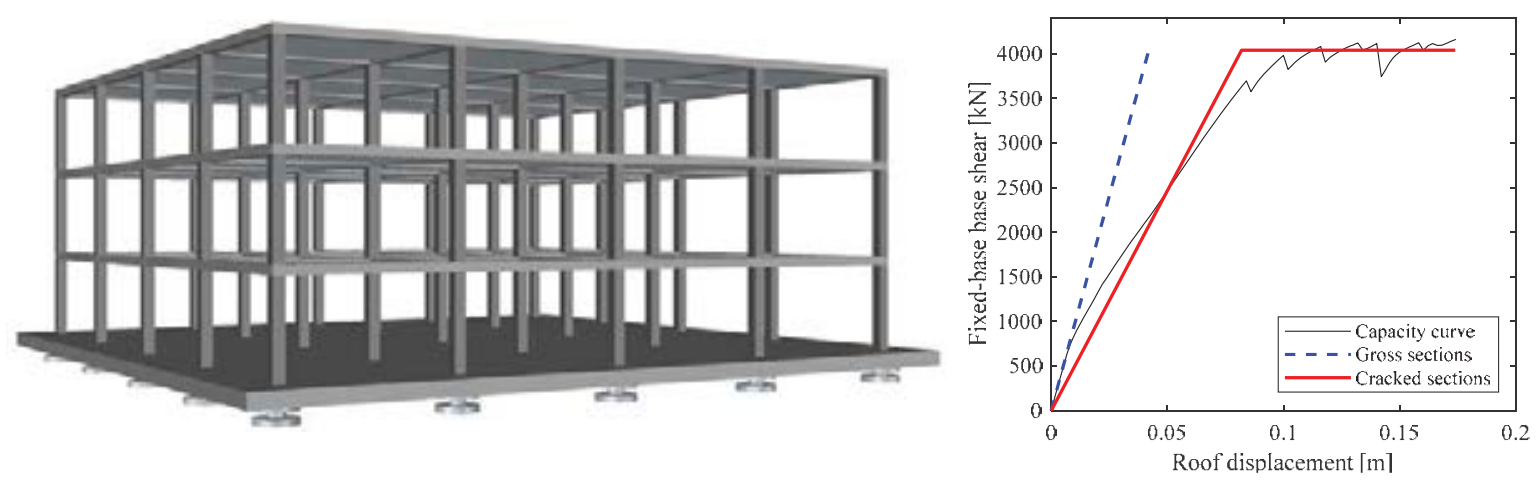

Figure 1: Case study structure.

The frame structure has four spans along both $\mathrm{x}$ and $\mathrm{y}$ directions with equal span length $(6 \mathrm{~m}$ each), and all floors have an interstorey height of $3 \mathrm{~m}$. Concerning the concrete slab, which represents the interface between the implemented isolation devices and the building, a thickness of 500mm has been adopted, and plan dimensions have been designed, by increasing the plan development of the superstructure of $1.5 \mathrm{~m}$ along all directions $(27 \mathrm{~m} \times 27 \mathrm{~m})$. For all the frame elements the flexural stiffness has been reduced, in order to better fit the linear-elastic branch of the bi-linear approximation of the capacity curve, as shown in Figure 1. The full capacity curve, in terms of base-shear vs. top displacement of the fixed-base configuration of the building has been obtained through a pushover analysis carried out through the software SeismoStruct ([15]), which allows to model force-based frame elements, with distributed plasticity and non-linear constitutive laws for materials (Mander's model for Concrete and Menegotto-Pinto's model for reinforcement steel); in addition, for concrete columns the proper confinement effects within the concrete core has been accounted for, in order to obtain realistic evaluation of both ductility and strength for all the implemented sections. Isolation devices are represented by Concave Surface Slider devices.

\section{CHARACTERISTICS OF THE PHYSICAL DEVICE}

The physical isolator consists of a Double Curved Surface Slider ([5]), which is actually the most typical configuration of sliding devices designed in real practice applications (Figure 2). Two spherical sliding surfaces with the same curvature radius have been implemented, both polished to mirror finish in order to achieve a roughness index Ra of 0,2 ([10]). Within the equal sliding surfaces, a non-articulated slider is installed, which is made up of a unique steel block (material S355JR): such an element houses two circular sliding pads, having same diameter $(360 \mathrm{~mm})$ and same material composition, aiming at considering the same contact pressure and the same frictional properties at both the sliding interfaces. Both the radii of curvature of the spherical surfaces are $1600 \mathrm{~mm}$ each, with internal slider height of $120 \mathrm{~mm}$ : consequently, the equivalent radius of curvature of the device is approximately equal to $3080 \mathrm{~mm}$.

The device has been equipped with an innovative sliding material, which consists of a graded PTFE material, filled with bronze fibers. In addition, the sliding surface of the pad has been realized with dimpled recesses, with a light lubrication, in order to achieve the proper design friction coefficient, equal to $3 \%$ ([4]); the corresponding value of applied vertical load is equal to $1500 \mathrm{kN}$. The maximum displacement, given the assumed plan geometric characteristics of sliding surfaces and internal slider, is equal to $172 \mathrm{~mm}$. 

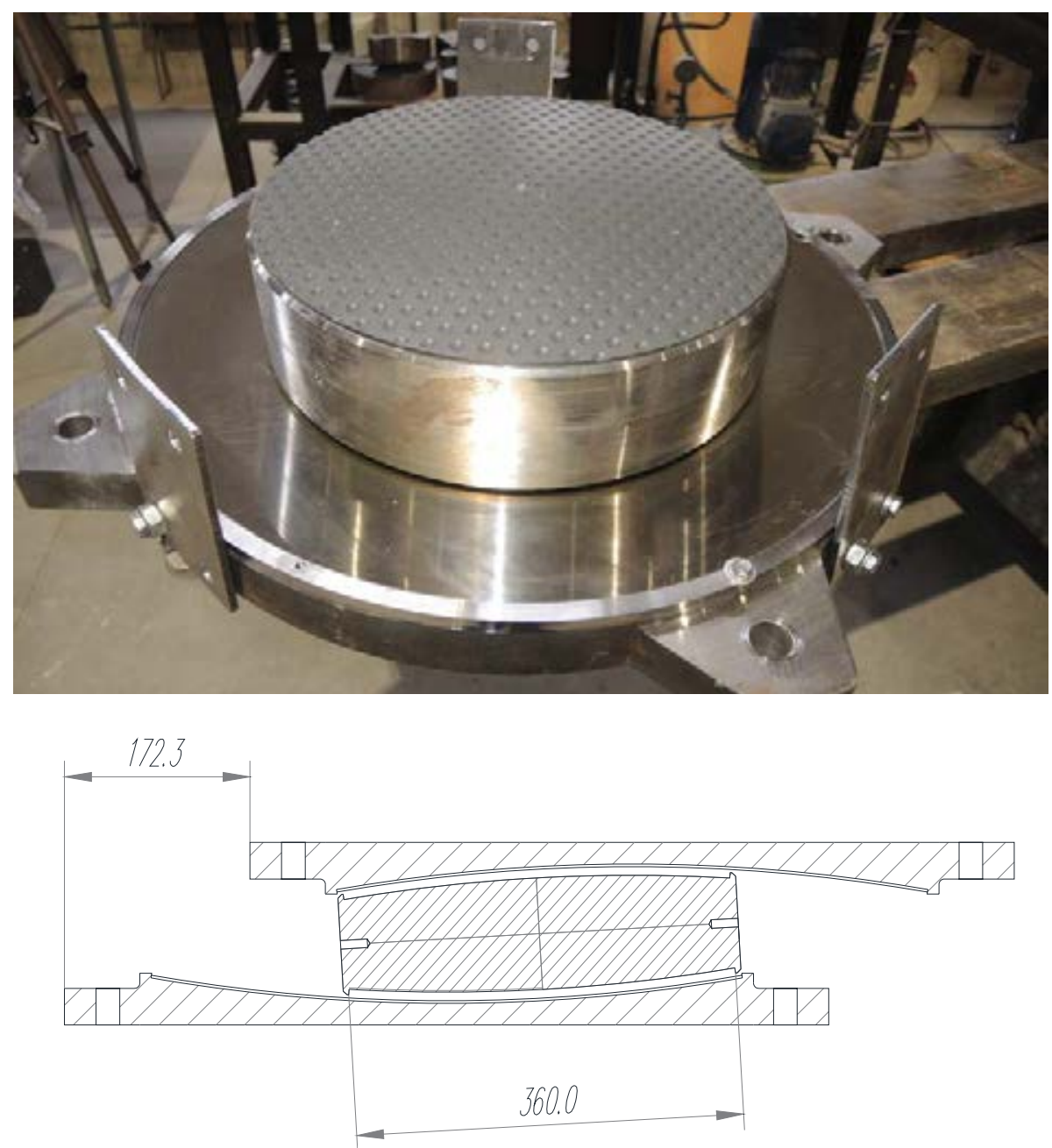

Figure 2: Tested physical device: definition of maximum displacement.

In order to consider a significant extra-stroke displacement demand, the maximum displacement to be considered for the simulation, which will define the proper scaling of the input signal, is defined according to the design value, increased by $50 \%$ of the sliding pad diameter, so that $25 \%$ of the pad is uncovered by each sliding surface ([6]). Thus, a maximum displacement of $350 \mathrm{~mm}$ has been considered.

\section{NUMERICAL SUBSTRUCTURE AND DYNAMIC SYSTEM}

The case study structure has been numerically modeled as an equivalent Multi Degree of Freedom oscillator, thanks to a special static condensation procedure, which has been applied to the full 3D FEM model of the structure ([9]). In Table 1 the resulting mass and stiffness matrices are reported.

\begin{tabular}{|c|c|c|c|}
\hline 941.3 & 0.0 & 0.0 & 0.0 \\
\hline 0.0 & 589.7 & 0.0 & 0.0 \\
\hline 0.0 & 0.0 & 589.7 & 0.0 \\
\hline 0.0 & 0.0 & 0.0 & 397.1 \\
\hline
\end{tabular}

\begin{tabular}{|c|c|c|c|}
\hline 236656 & -329731 & 111851.3 & -18776.6 \\
\hline-329731 & 617351.8 & -377915 & 90295.5 \\
\hline 111851.3 & -377915 & 479479.9 & -213416 \\
\hline-18776.6 & 90295.5 & -213416 & 141894.8 \\
\hline
\end{tabular}

Table 1: Mass (left [tons]) and stiffness (right $[\mathrm{kN} / \mathrm{m}]$ ) condensed matrices for the case study structure. 
Such matrices allow to obtain dynamic properties almost overlapped of the ones related to the full FEM model,: this result is a direct consequence of the adopted static condensation procedure, which allows to account for the actual flexural behavior in the out-of-plane direction for beams, together with torsional behavior of each floor. It is important to highlight that the response of the isolation system is not modeled by the stiffness matrix, since that contribution needs to be accounted for separately, especially for the hybrid simulation.

For both the hybrid test and the numerical simulation, the superstructure has been modeled through the definition of the aforementioned equivalent multi degree of freedom (MDOF) oscillator, with statically condensed mass and stiffness matrices. By adopting such matrices the actual dynamic properties of the overall structural systems are effectively reproduced, and approximately the same response of the full 3D FEM model can be obtained. Consequently, the dynamic system can be expressed as follows:

$$
\overline{\bar{M}} \cdot\left(\begin{array}{l}
\frac{\ddot{u}_{0}}{\ddot{u}_{1}} \\
\ddot{u}_{2} \\
\ddot{u}_{3}
\end{array}\right)+\left(\begin{array}{l}
\frac{u_{0}}{u_{1}} \\
u_{2} \\
u_{3}
\end{array}\right)+\left\langle F_{i s}\right\rangle \cdot\left(\begin{array}{l}
\frac{1}{0} \\
0 \\
0
\end{array}\right)=-\overline{\bar{M}} \cdot\left(\begin{array}{l}
\underline{1} \\
1 \\
1 \\
1
\end{array}\right) \cdot \ddot{x}_{g}
$$

Given:

- $\overline{\bar{M}}$ the condensed mass matrix of the system;

- $\overline{\bar{K}}$ the condensed stiffness matrix of the system;

- $u_{i}$ the translational degrees of freedom at the centre of mass location of the i-th floor;

- $\ddot{x}_{g}$ the considered ground acceleration time series;

- $\left\langle F_{i s}\right\rangle$ the isolation force response.

A very low additional viscous damping has been considered for both simulations, namely $2 \%$, modeled by means of the Rayleigh formulation, in order not to underestimate the overall response. The isolation system is considered separately in the dynamic system, and it is modeled as a single device, representative of the whole set of isolators. For the hybrid simulation, the isolation force is computed as a function of the force feedback of the Bearing Tester System, which is then scaled by the ratio between the total structural weight of the system and the applied vertical load to the device. On the other hand, in the numerical simulations, the following analytical expression can be adopted:

$$
\left\langle F_{i s}\right\rangle=W_{t o t} \cdot\left(\frac{u_{0}}{R_{e q}}+k_{\mu} \cdot \mu \cdot f_{N F}\right)
$$

Being:

- $\mathrm{W}_{\text {tot }}$ the total structural weight of the system;

- $\mathrm{R}_{\mathrm{eq}}$ the equivalent radius of curvature of the device;

- $u_{0}$ the translational degree of freedom at the centre of mass location of the concrete slab (isolation level);

- $\mu$ the design friction coefficient;

- $f_{N F}$ a normalized frictional hysteretic parameter;

- $k_{\mu}=\mu / \mu_{o}$ a variation scale factor of the friction coefficient. 
In order to model the frictional hysteretic response, a hysteretic parameter $f_{N F}$ has been adopted, by assuming an elasto-plastic rule (Figure 3).
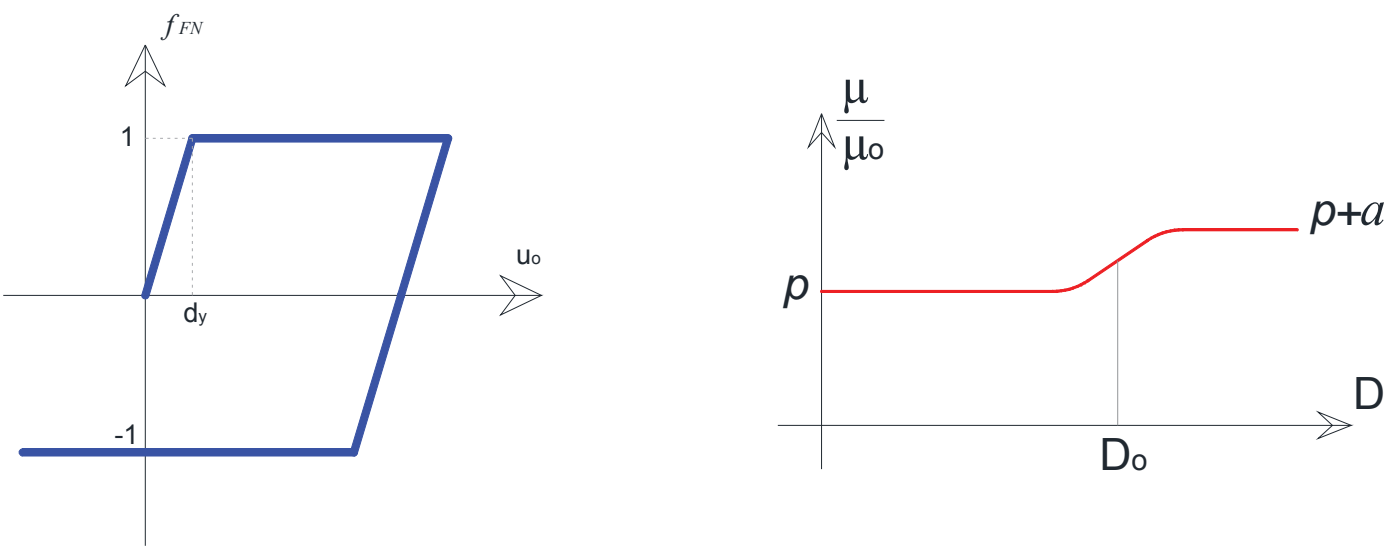

Figure 3: Analytical model of the frictional hysteretic (left) and extra-stroke (right) responses.

Since the overall system is supposed to be subjected to a sever seismic input, and consequently the design displacement of the isolation system is expected to be overcome, the extra-stroke behavior needs to be numerically modeled. Recent research works ([6], [8]) have shown good agreement between some experimental outcomes pseudo-dynamic tests in extra-stroke range for DCSS devices and possible numerical modeling strategies, namely:

- Analytical expression of the friction coefficient increase, for easy and fast structural assessments;

- An opensees link element for the extra-stroke response;

- An opensees link element, modeled for variable friction sliding isolators.

In this work the first strategy has been considered, by applying an analytical function, which increases the friction coefficient value, as the design displacement is exceeded. The increment of the friction coefficient in the extra-stroke range has been assumed equal to $50 \%$.

\section{SEISMIC INPUT}

The input signal for both numerical and experimental hybrid simulations has been selected within the REXEL database ([11]), by checking the peak displacement of an equivalent Single Degree of Freedom (SDOF) system, with the non-linear hysteretic constitutive law of the implemented isolation system. The scale factor of the seismic event has been computed, aiming at obtaining a maximum displacement less than $350 \mathrm{~mm}$, which corresponds to the maximum displacement in the extra-stroke range considered in this study. A seismic event with a limited scale factor has been adopted, so that a realistic balance between amplitude and frequency content of the signal is ensured. Below the main characteristics of the selected earthquake are listed:

- Earthquake Name: Gazli

- Station ID: KAR

- Component: $x$ 
- Mw: 6.7

- Fault Mechanism: reverse

- Epicentral Distance [km]: 12.78

- Original PGA [g]: 0.717

- Scaled PGA [g]: 0.789

- Scale Factor [\#]: 1.1

In Figure 4 graphical properties of the seismic event used for all the simulations are provided, in terms of time series of ground displacement and acceleration, together with the acceleration response spectrum at 5\% damping.
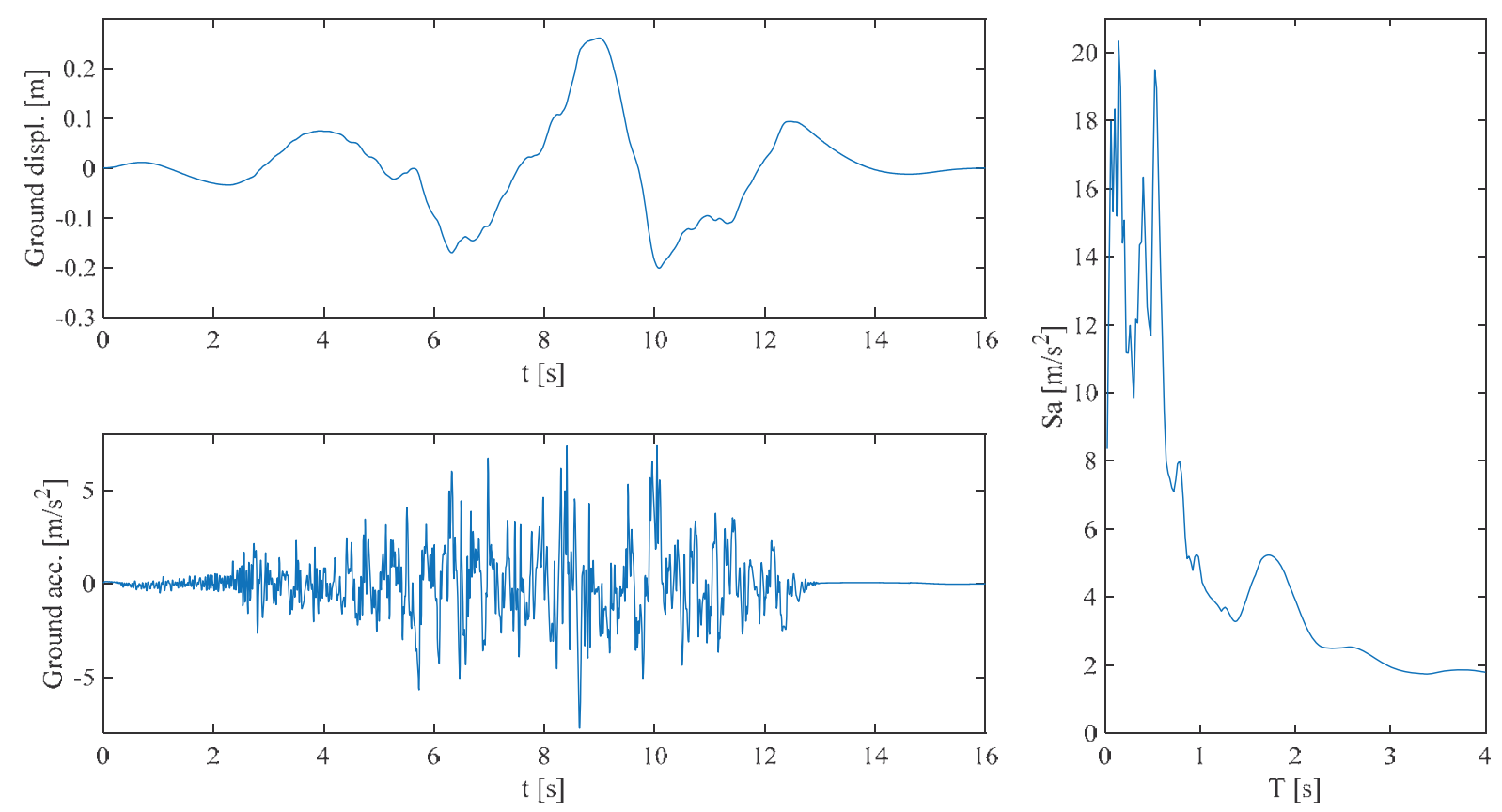

Figure 4: Characteristics of the adopted seismic event.

The resulting response spectrum show significantly high spectral coordinates at low periods, whereas more limited values can be noticed for high period values, much more related to the designed isolated system.

The hybrid simulation has been carried out by considering the superstructure as the aforementioned MDOF oscillator as a numerical substructure, whereas the full-scale device tested within the Bearing Tester System has been considered as the physical substructure, to carry out an earthquake simulation. To do so, within the hybrid simulation algorithm a time scale factor equal to 32 has been adopted.

\section{RESULTS}

Results of both numerical and experimental hybrid simulations are compared in this section, by focusing the attention on the isolation response, in terms of displacement demand and hysteretic behavior, and damage evidence at the implemented sliding pads has been checked after the test. In addition, the response of the superstructure has been analyzed, in order to assess if 
the building has been subjected to excitations within the linear-elastic range. In Figure 5 the displacement time series of the isolation layer are compared, with respect to the design value.

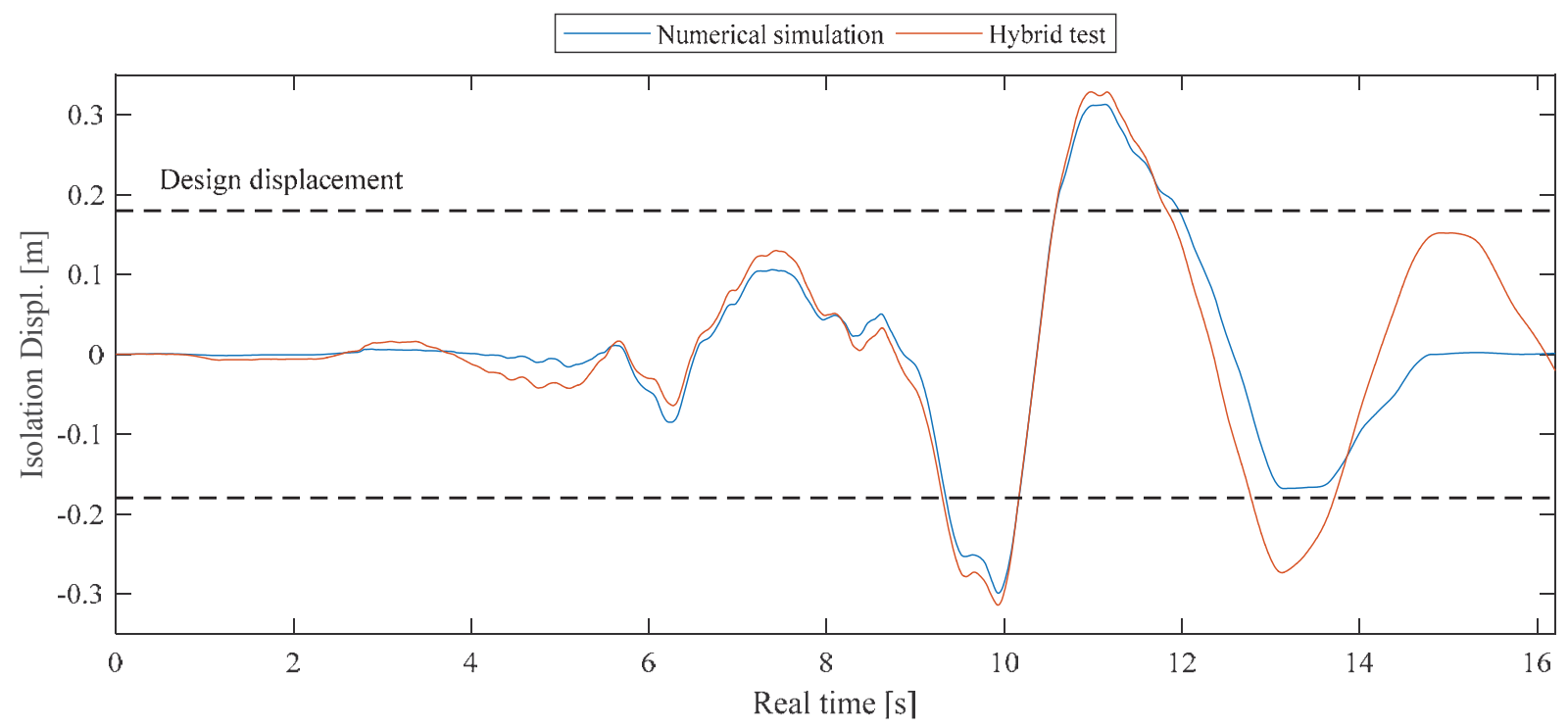

Figure 5: Isolation displacement response.

In Figure 6 the hysteretic response of the isolation system is provided, in terms of isolation force, normalized with respect to the total weight of the whole structural system.

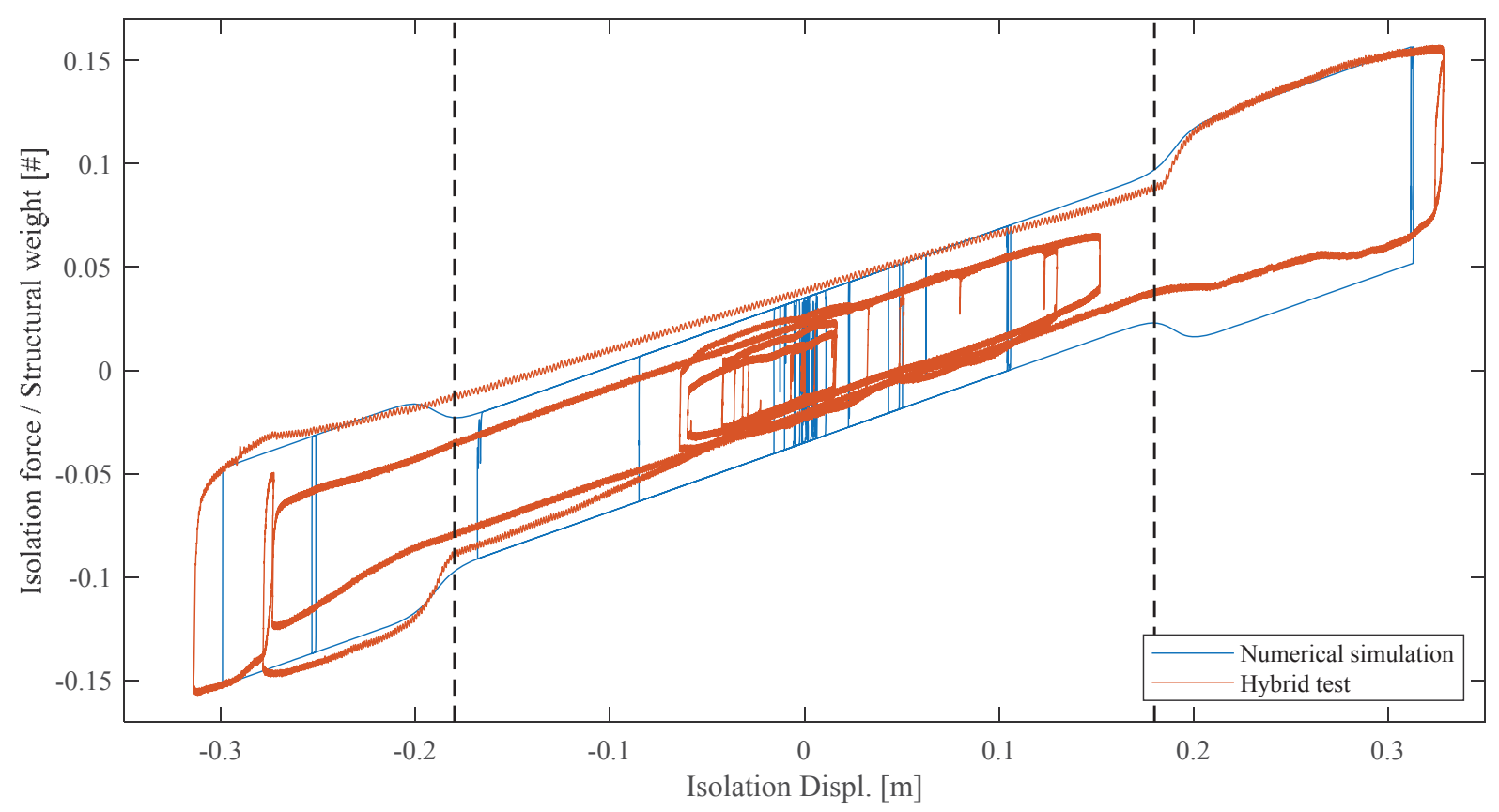

Figure 6: Isolation hysteretic behavior.

In Figure 7 the damage evidence at the sliding pad at the end of the experimental hybrid test are shown. 


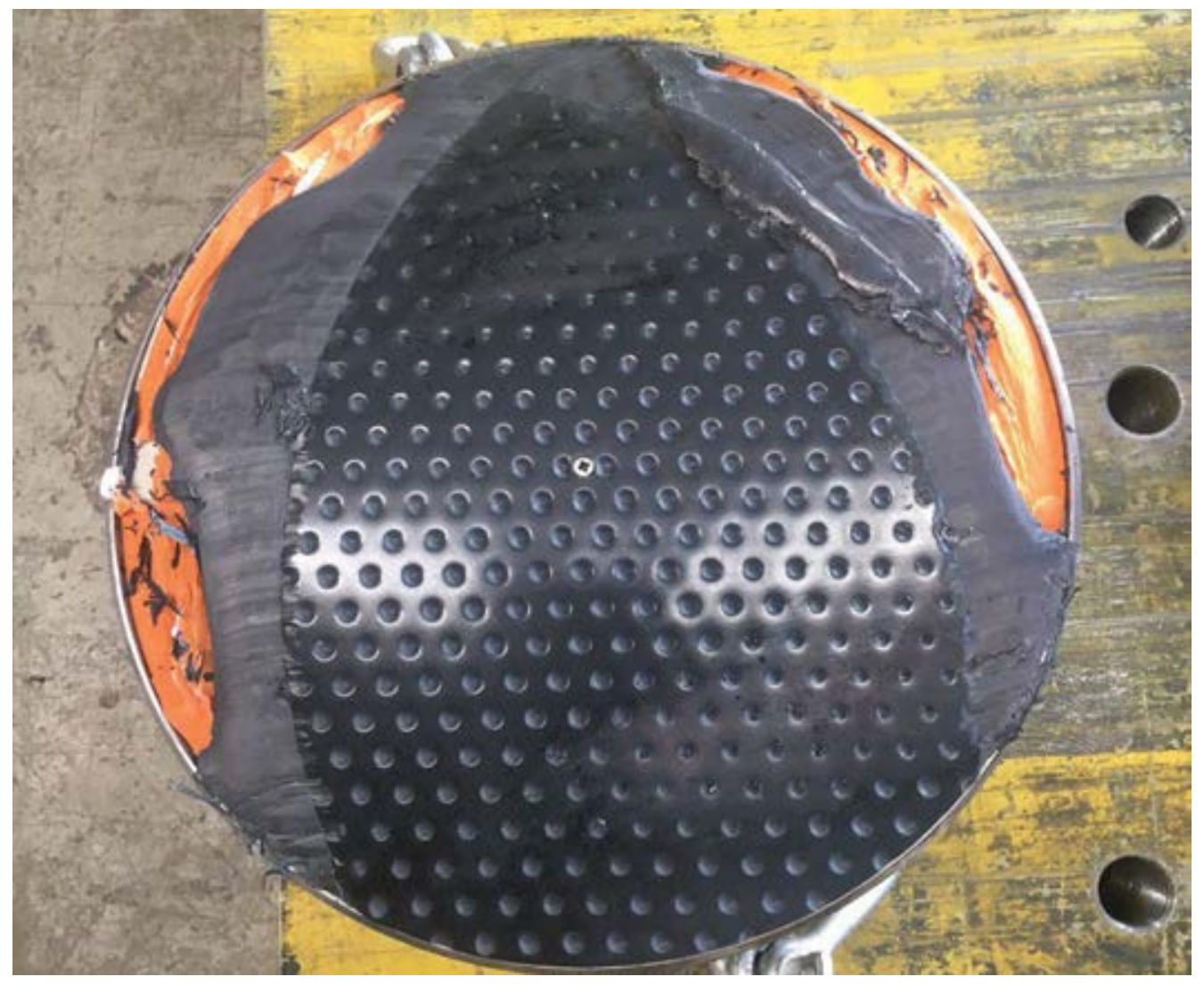

Figure 7: Damage evidence at the sliding pads.

In the hybrid simulation the full scale device has been subjected to displacement demands higher than the design value three times, at three consecutive peak displacement, under an approximately harmonic motion. The numerical simulation shown approximately an overlapped signal, exception made for the very last portion of the seismic event, where the design displacement is experimentally exceeded for the third time: at those time instants the numerical simulation returns lower displacement values, within the ordinary response of the isolator. The main reason of this final mismatching could be addressed to the degradation of the friction coefficient, which can be graphically noticed in the hysteretic response. Due to the subsequent extra-stroke displacement demands, significant damage occurs at the sliding interfaces, and this results into an increased pressure (caused by detachments of sliding material) and to a continuously decreasing friction coefficient. The degradation of the frictional properties finally leads to higher displacement demands, in comparison to the purely numerical model, which accounts for a constant friction coefficient. Nonetheless, for almost the whole duration of the simulation, the numerical model provides approximately overlapped signals, from both displacement and hysteretic responses, with a good estimate of the peak parameters. The increase of the friction coefficient modeled in the numerical simulation $(+50 \%)$ due to the extra-stroke behavior fairly capture the experimental response of the full device in the hybrid test. Thus, results for the isolation system seems to suggest that the frictional properties may be influenced by the extra-stroke behavior, depending on the number of subsequent displacement demands exceeding the design value and, consequently, on the entity of the cumulative damage at the sliding pad.

Finally, in Figure 8 the building response is shown. 

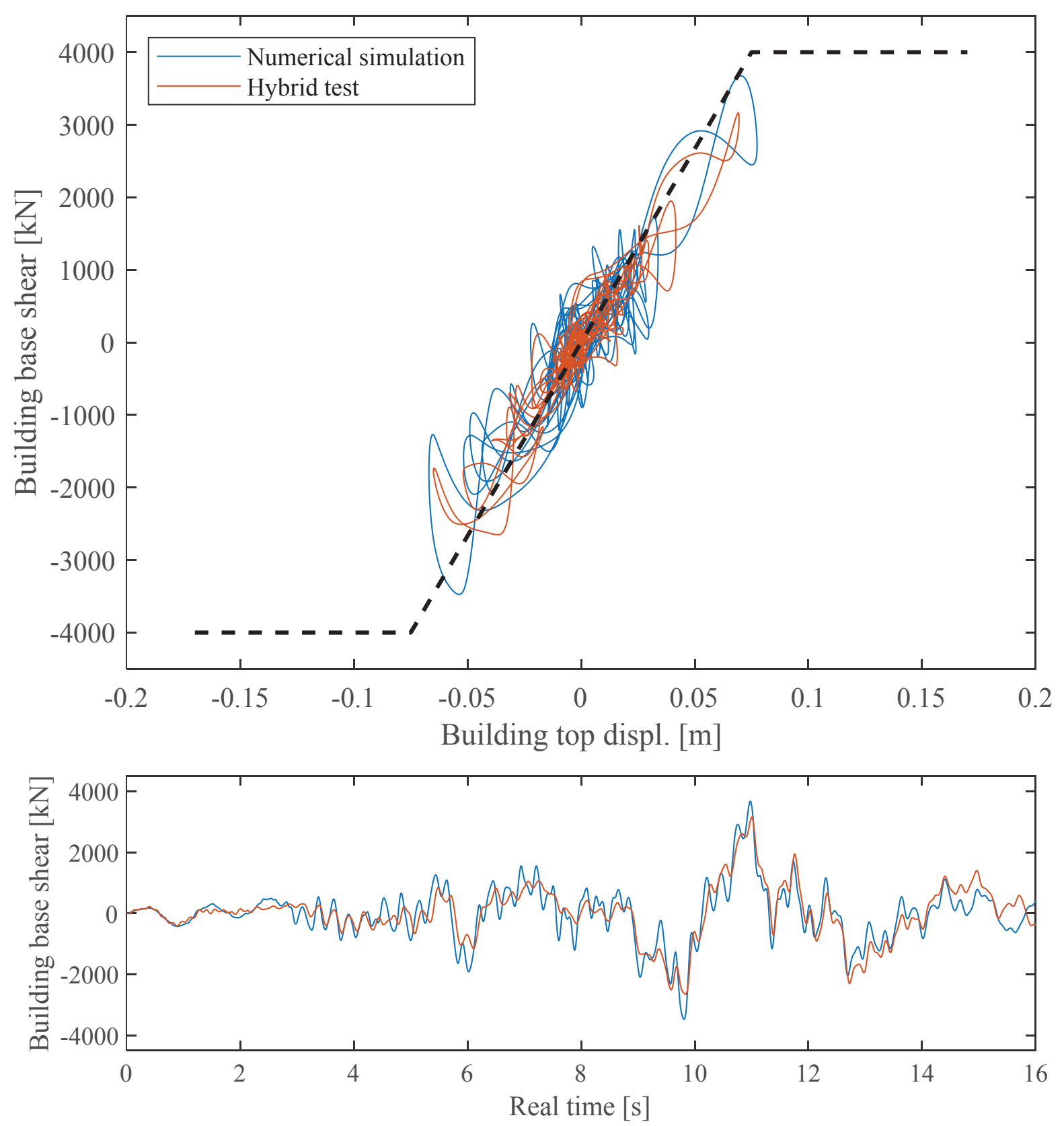

Figure 8: Building base shear response.

The building base shear response seems not to be significantly influenced by extra-stroke displacement demands at the isolation system, mainly because of the smooth increase of the friction coefficient which occurs, when the design displacement is overcome, according to the technology of devices under investigation. In addition, for the whole duration of the simulations, the building response is within the linear-elastic range, and confirm that the modeling assumptions of the MDOF system of the superstructure is fairly good for the considered system. The numerical simulation returns a slightly higher response in comparison to the experimental hybrid test, even though signals are very close one to each other. 


\section{CONCLUSIONS}

In this work the response of a base isolated case study structure has been assessed, through a numerical simulation, by assuming an extreme seismic event. Specifically, the system has been subjected to an ad hoc selected earthquake, in order to overcome the design displacement at the isolation layer. The obtained results have been compared to the outcomes of a corresponding experimental hybrid test, in which the superstructure model represents the numerical substructure, whereas as a physical substructure a full-scale device has been tested within the Bearing Tester System of the Laboratory of EUCENTRE Foundation in Pavia (Italy). In the numerical simulation the extra-stroke behavior has been modeled by means of a specific function, which increases the friction coefficient, as the design displacement is overcome.

By analyzing both the experimental and numerical results, the following findings can be found:

- The numerical model can fairly represent the effective experimental hysteretic behavior of the physical device, when subjected to extra-design displacement demands;

- The displacement time series at the isolation level returned by the numerical simulation is approximately overlapped, in comparison to the outcomes of the hybrid test, exception made for the last phase of the event;

- Toward the end of the earthquake simulation, the numerical model underestimates the displacement response, with displacements within the ordinary stroke of the device, in comparison to the hybrid test, which show an additional extra-design displacement at the same time instants;

- The main reason for possible mismatching at the end of the seismic event could be addressed to the cumulative damage which develops at the implemented sliding pads: due to an increase of the contact pressure the friction coefficient value decreases, and consequently larger displacement demands can be found, in comparison to the numerical simulation which accounts for a constant friction coefficient in the ordinary response;

- Thus, subsequent extra-design displacement demands could lead to excessive cumulative damage, which may imply degradations of the frictional properties;

- The extra-stroke behavior seems to have negligible effects on the building response, in terms of base shear and top displacement signals.

Further experimental investigations are needed on the topic, in order to highlight eventual dependencies of the extra-stroke behavior on the common response parameters considered to characterize sliding isolators, such as sliding velocity and vertical load.

\section{ACKNOWLEDGMENTS}

Part of the current work has been carried out under the financial support Italian Civil Protection, within the framework of the Executive Project DPC-EUCENTRE 2018 (Project 3 Assessment of the seismic isolation of buildings through hybrid experimental/numerical simulations) and ReLUIS project 2019-2021 (WP15, Task 15.1). 


\section{REFERENCES}

[1] Castaldo, P., Palazzo, B., Ferrentino, T. (2017) Seismic reliability-based ductility demand evaluation for inelastic base-isolated structures with friction pendulum devices, Earthquake Engineering and Structural Dynamics, 46(8), 1245-1266

[2] Castaldo, P., Palazzo, B., Alfano, G., Palumbo, M.F. (2018) Seismic reliability-based ductility demand for hardening and softening structures isolated by friction pendulum bearings, Structural Control and Health Monitoring, 25(11), e2256

[3] De Domenico D., Ricciardi G., Benzoni G. (2018) Analytical and finite element investigation on the thermo-mechanical coupled response of friction isolators under bidirectional excitation, Soil Dynamics and Earthquake Engineering, 106, 131-147.

[4] Dolce M, Cardone D, Croatto F (2005) Frictional behavior of steel-PTFE interfaces for seismic isolation. Bulletin of Earthquake Engineering, 3, 75-99.

[5] Fenz D, Constantinou MC, Behaviour of the double concave friction pendulum bearing. Earthquake Engineering And Structural Dynamics, 35,1403-1424, 2006.

[6] Furinghetti M., Yang T., Calvi P.M., Pavese A. (2021) Experimental evaluation of extra-stroke displacement capacity for curved surface slider devices. Soil Dynamics and Earthquake Engineering, https://doi.org/10.1016/j.soildyn.2021.106752.

[7] Peng Y., Ma Y., Huang T., De Domenico D (2021) Reliability-based design optimization of adaptive sliding base isolation system for improving seismic performance of structures, Reliability Engineering \& System Safety, DOI: https://doi.org/10.1016/j.ress.2020.107167.

[8] Ponzo F.C., Di Cesare A.,Telesca A., Pavese A., Furinghetti M. (2021) Advanced Modelling and Risk Analysis of RC Buildings with Sliding Isolation Systems Designed by the Italian Seismic Code. Applied Sciences, https://doi.org/10.3390/app11041938.

[9] Furinghetti M., Lanese I., Pavese A. (2020) Experimental assessment of the seismic response of a base isolated building through hybrid simulation technique, Frontiers in Built Environment, DOI: 10.3389/fbuil.2020.00033.

[10] Furinghetti M, Pavese A, Quaglini V, Dubini P (2019) Experimental Investigation Of The Cyclic Response Of Double Curved Surface Sliders Subjected To Radial And Bidirectional Sliding Motions. Soil Dynamics and Earthquake Engineering, DOI: https://doi.org/10.1016/j.soildyn.2018.11.020.

[11] Iervolino I, Galasso C, Cosenza E (2009), REXEL: computer aided record selection for code-based seismic structural analysis. Bulletin of Earthquake Engineering, DOI: 10.1007/s10518-009-9146-1.

[12] Kumar M, Whittaker AS, Constantinou MC (2015) Characterizing friction in sliding isolation bearings. Earthquake Engineering and Structural Dynamics, 44,1409-1425.

[13] Lomiento G, Bonessio N, Benzoni G, Concave sliding isolator's performance under multi-directional excitation. Ingegneria Sismica, 30:3,17-32, 2013.

[14] Mazza F, Mazza M (2017) Sensitivity to modelling and design of curved surface sliding bearings in the nonlinear seismic analysis of base-isolated r.c. framed buildings. Soil Dynamics and Earthquake Engineering, 79, 951-970. 
[15] Seismosoft. SeismoStruct 2016 - A computer program for static and dynamic nonlinear analysis of framed structures. 2016, available from http://www.seismosoft.com.

[16] Tsiavos A, Sextos A, Stavridis A, Dietz M, Dihoru L, Nicholas A. (2020) Large-scale experimental investigation of a low-cost PVC 'sand-wich' (PVC-s) seismic isolation for developing countries. Earthquake Spectra 36(4),1886-911. 